\title{
The Bipartient Tendency of the Articular Surface of the Trochlear Notch in the Human Ulna
}

\author{
By \\ Bin Yamaguchi \\ Department of Anatomy, Sapporo Medical College \\ Sapporo, Japan \\ -Received for Publication, July 31, 1971-
}

\section{Introduction}

The articular surface of the trochlear notch has long been known to have a tendency toward the bipartition into the olecranon part and the coronoid process part by the osseous surfaces encroaching from the medial and/or the lateral sides (e.g. Henle 1871, Fischer 1906, Heine 1925).

So far in anthropological studies of dry ulnae, the variability in this bipartient tendency of the trochlear notch surface has been classified into two or three categories: continuous, partially divided, and completely divided (e.g. Manouvrier \& Anthony 1907, Kutsuna 1930, Anderson 1963). Occasionally a fourth category, the scaly ossicle, has been added to the above classification (e.g. Kiyono \& Hirai 1928, Mizoguchi 1957). The latter ossicle, however, has been treated rather separately from the bipartient tendency in most dry bone studies, though it was indicated by a histological study (Heine 1925) that the bony tubercle was in close relationship with the formation of the transverse bony groove.

The present author, while investigating the osteological material excavated from an early historical Ontario Iroquoian ossuary site in the University of Toronto, has found the routine trichotomic classification inadequate for the reality of wide variability in the structure of this articular surface. This led him to devise a new tentative scheme of classification comprising 7 different categories as shown in Fig. 1.

As the Iroquoian ulnae investigated were of a secondary group burial material, neither the combination of right and left sides nor the age and sex of individuals could be estimated with reasonable reliability. Therefore, the author attempted to confirm the classificatory sequence from the type (1) to the type (7) by surveying the 
side combination of the bipartient types in the same individuals on a well-documented collection of modern Japanese skeletons in Sapporo. During the course of study on the Iroquoian and Japanese materials, the author was led to suspect a possible relationship between the bipartient tendency and the age of skeleton. This has also been investigated on the same Japanese skeletal material with known sex and age.

\section{Material}

Although the initial steps of this work were derived from the osteological survey of nearly 200 right ulnae from an historical Iroquoian ossuary in Carton site, Milton, Ontario, Canada, during the author's stay in Toronto, the main portion of this work has been done on an anatomical collection of 130 macerated modern Japanese skeletons in Sapporo. The majority of the skeletons belong to the Department of Anatomy in the University of Chiba and are temporarily loaned to Sapporo Medical College.

The total series of 130 skeletons ranges in age from 17 years to 84 years, and consists of 100 male and 30 female skeletons. Provenances are concentrated to the central part of Honshu.

In addition to these two series, 168 ulnae of the Hokkaido Ainu collected in Sapporo Medical College and the University of Tokyo were also examined for the incidences of 7 bipartient types of the trochlear notch to be compared with those in the former series of ulnae.

\section{Morphological Classification}

In Fig. 1, two extreme cases, the articular surface with no bipartient tendency and the one completely separated into two facets by a transverse osseous groove, are placed at the left and the right ends, and all intermediate forms found in the Indian and Japanese ulnae are arranged between these two extremes according to a morphological sequence of bipartient tendency. Description of these seven different types follows.

1) The articular surface on the olecranon part continues smoothly to that on the coronoid process, and neither the medial nor the lateral triangular bony surface reaches the central guiding ridge.

2) The articular surface is more or less divided into two parts by a groove or a faint ridge or a sort of cresse, or a combination of these structures, which are covered with the articular cartilage. Otherwise the same with (1). For the sake of convenience, these cartilage-covered demarcating structures will be collectively called 


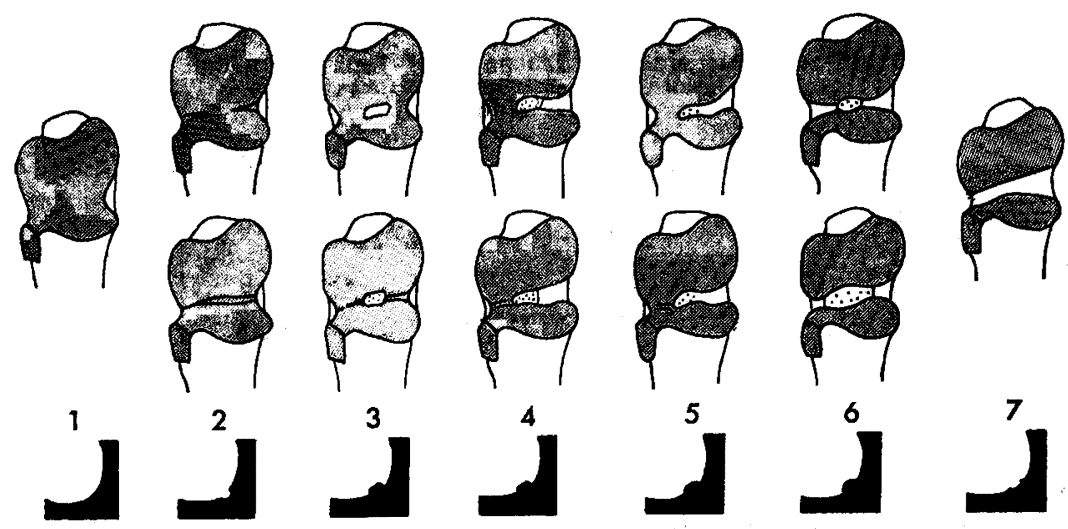

Fig. 1. A sequential classification of the various types of bipartient tendency of the articular surface of the trochlear notch (see the text for explanation). Silhouettes at the bottom are the sagittal sections through the middle of the notch.

the cartilaginous crease hereafter.

3) A well bounded tiny ossicle elevated about $1 \mathrm{~mm}$ above the normal calcified layer of the articular surface is formed in the middle part of the demarcating line between the two parts. At the medial and lateral sides of this ossicle, the articular surface may be continuous, or partially or completely separated by the cartilaginous erease.

4) The medial (or lateral) bony notch reaches the above ossicle leaving the other side continuous or separated only by cartilaginous crease.

5) The surfaces of the ossicle and the medial (or lateral) notch are so continuous that the bony notch seems to have invaded beyond the central guiding ridge. The other side the same with the type (4).

6) The medial and lateral bony notches reach the ossicle and divide the trochlear notch surface completely into two facets. The ossicle may be clearly discernible or may be ambiguous, but the middle part of these bony demarcating structures is more or less elevated above the normal articular surface as shown in the sagittal section.

7) Perfect bipartition by an osseous groove.

\section{Bilateral Association of the Types}

In order to confirm the validity of such sequent classification, a table of bilateral association of the types was made for 125 Japanese skeletons with the trochlear notches of both sides intact. As the type (7) was not found in Japanese material and the type (5) which 
Table 1. Association of the bipartient types between right and left sides in 125 pairs of Japanese ulnae.

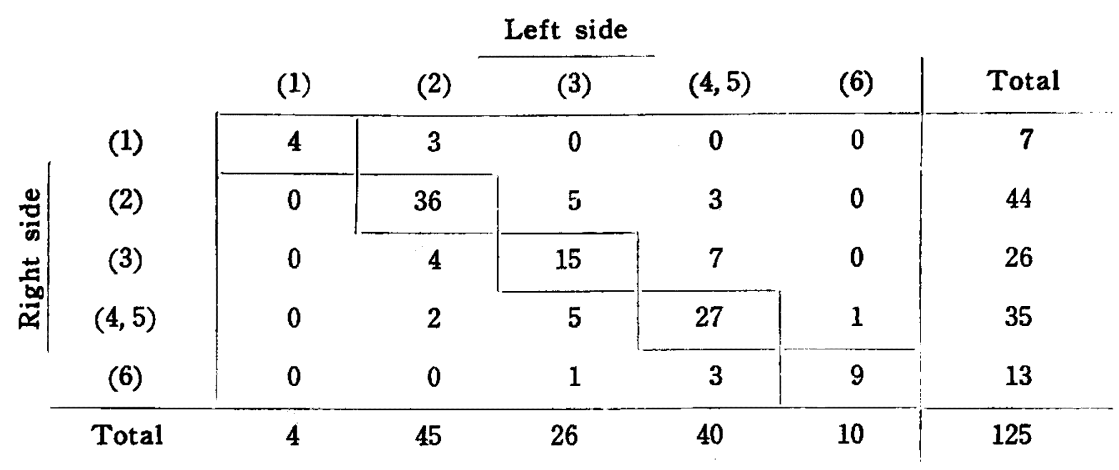

is similar to the type (4) was rather infrequent, only a condensed table including types (1), (2), (3), $(4,5)$, and (6) is shown above (Table 1).

The table clearly shows that the type (1) is associated only with the type (2); the type (3) almost solely with the types $(2)$ and $(4,5)$; and the type (6) mainly with the types $(4,5)$. Generally, the combinations of types between right and left sides strongly confirm the hypothetical sequence of the morphological types as shown in Fig. 1.

It may be said incidentally that the validity of this sequent classification justifies the pooling of adjacent types for the purpose of intensifying the power of statistical tests of incidences in the following discussions.

\section{Incidence Data for the Japanese Material}

Basic adult incidence data for each sex and each side and for pooled sides and pooled sexes are given in Table 2. As mentioned in the previous chapter, no case was found for the type (7) in the present Japanese material.

In 77 ulnae showing either of the type (4) or (5), the bony notch develops from the medial side in 64 cases (83.1\%), and only in 13 cases $(16.9 \%)$ it develops from the lateral side.

As the differences between right and left sides were not significant in both sexes (by chi-square test at the level of 5 percent.), the right and left ulnae were combined for each sex, and the sex difference in the incidences of the bipartient types was tested by the following contingency table (Table 3).

The table suggests that those types of more marked bipartient tendency $(4,5,6)$ are considerably more frequent in the male than in the female ulnae, whereas the latter generally show less marked 
Table 2. Frequencies of the bipartient types of the trochlear notch in adult Japanese ulnae.

\begin{tabular}{|c|c|c|c|c|c|c|c|}
\hline Types & (1) & (2) & (3) & (4) & (5) & (6) & Total \\
\hline \multicolumn{8}{|l|}{ Male } \\
\hline $\begin{array}{l}\text { Right } \\
(\%)\end{array}$ & $\begin{array}{c}4 \\
(4.2)\end{array}$ & $\begin{array}{c}28 \\
(29.2)\end{array}$ & $\begin{array}{c}22 \\
(22.9)\end{array}$ & $\begin{array}{c}28 \\
(29.2)\end{array}$ & $\begin{array}{c}2 \\
(2.1)\end{array}$ & $(12.5)$ & $\begin{array}{c}96 \\
(100)\end{array}$ \\
\hline $\begin{array}{l}\text { Left } \\
(\%)\end{array}$ & $(1.0)$ & $\begin{array}{c}30 \\
(30.9)\end{array}$ & $\begin{array}{c}21 \\
(21.6)\end{array}$ & $\begin{array}{c}35 \\
(36.1)\end{array}$ & $\begin{array}{c}1 \\
(1.0)\end{array}$ & $(9.3)$ & $\begin{array}{c}97 \\
(100)\end{array}$ \\
\hline $\begin{array}{l}\text { R\&L } \\
(\%)\end{array}$ & $\begin{array}{c}5 \\
(2.6)\end{array}$ & $\begin{array}{c}58 \\
(30.1)\end{array}$ & $\begin{array}{c}43 \\
(22.3)\end{array}$ & $\begin{array}{c}63 \\
(32.6)\end{array}$ & $(1.6)$ & $\begin{array}{c}21 \\
(10.9)\end{array}$ & $\begin{array}{l}193 \\
(100)\end{array}$ \\
\hline \multicolumn{8}{|l|}{ Female } \\
\hline $\begin{array}{l}\text { Right } \\
(\%)\end{array}$ & $\stackrel{2}{(6.7)}$ & $\begin{array}{c}16 \\
(53.3)\end{array}$ & $\begin{array}{c}5 \\
(16.7)\end{array}$ & $\begin{array}{c}5 \\
(16.7)\end{array}$ & $\left(\begin{array}{c}1 \\
(3.3)\end{array}\right.$ & $\left(\begin{array}{c}1 \\
(3.3)\end{array}\right.$ & $\begin{array}{c}30 \\
(100)\end{array}$ \\
\hline $\begin{array}{l}\text { Left } \\
(\%)\end{array}$ & $\begin{array}{c}2 \\
(6.7)\end{array}$ & $\begin{array}{c}16 \\
(53.3)\end{array}$ & $(20.0)$ & $\begin{array}{c}5 \\
(16.7)\end{array}$ & $\begin{array}{c}0 \\
(0)\end{array}$ & $\begin{array}{c}1 \\
(3.3)\end{array}$ & $\begin{array}{l}30 \\
(100)\end{array}$ \\
\hline $\begin{array}{l}\text { R\&L } \\
(\%)\end{array}$ & $\begin{array}{c}4 \\
(6.7)\end{array}$ & $\begin{array}{c}32 \\
(53.3)\end{array}$ & $\begin{array}{c}11 \\
(18.3)\end{array}$ & $(16.7)$ & $\begin{array}{c}1 \\
(1.7)\end{array}$ & (3. 3 ) & $\begin{array}{c}60 \\
(100)\end{array}$ \\
\hline \multicolumn{8}{|l|}{$\mathrm{M} \& \mathrm{~F}$} \\
\hline $\begin{array}{l}\mathrm{R \& L} \\
(\%)\end{array}$ & $\begin{array}{c}9 \\
(3.6)\end{array}$ & $\begin{array}{c}90 \\
(35.6)\end{array}$ & $\begin{array}{c}54 \\
(21.3)\end{array}$ & $\begin{array}{c}73 \\
(28.9)\end{array}$ & $\begin{array}{c}4 \\
(1.6)\end{array}$ & $\stackrel{23}{(9.1)}$ & $\begin{array}{l}253 \\
(100)\end{array}$ \\
\hline
\end{tabular}

Table 3. Test of sex difference. (Incidences in both sides are pooled.)

\begin{tabular}{|c|c|c|c|c|}
\hline Types & $(1,2)$ & (3) & $(4-6)$ & Total \\
\hline Male & 63 & 43 & 87 & 193 \\
\hline Female & 36 & 11 & 13 & 60 \\
\hline \multirow[t]{2}{*}{ Total } & 99 & 54 & 100 & 253 \\
\hline & $\chi_{c}^{2}=15$ & & $\mathrm{P}<0.01$ & \\
\hline
\end{tabular}

tendency toward bipartition. In fact, the corrected chi-square value is significant at the level of 1 percent. The result forces the author to deal with the sexes separately in further analyses.

\section{Relation with the Age Factor}

Type incidences in three different age groups: $x-39,40-59$, and 60-x years, are given in Table 4. Stronger bipartient types (4-6) occur more frequently in higher ages. Chi-square tests of appropriately condensed contingency tables revealed significant differences between the age groups 17-39 and 40-59 and between 40-59 and 60-84 in the male at 0.01 level and a significant difference between 20-59 and 60-81 in the female at 0.05 level. Kutsuna (1930) reported a similar gradual increase of the incidence of the complete separation 
Table 4. Incidences of the bipartient types in difterent age groups (sides pooled).

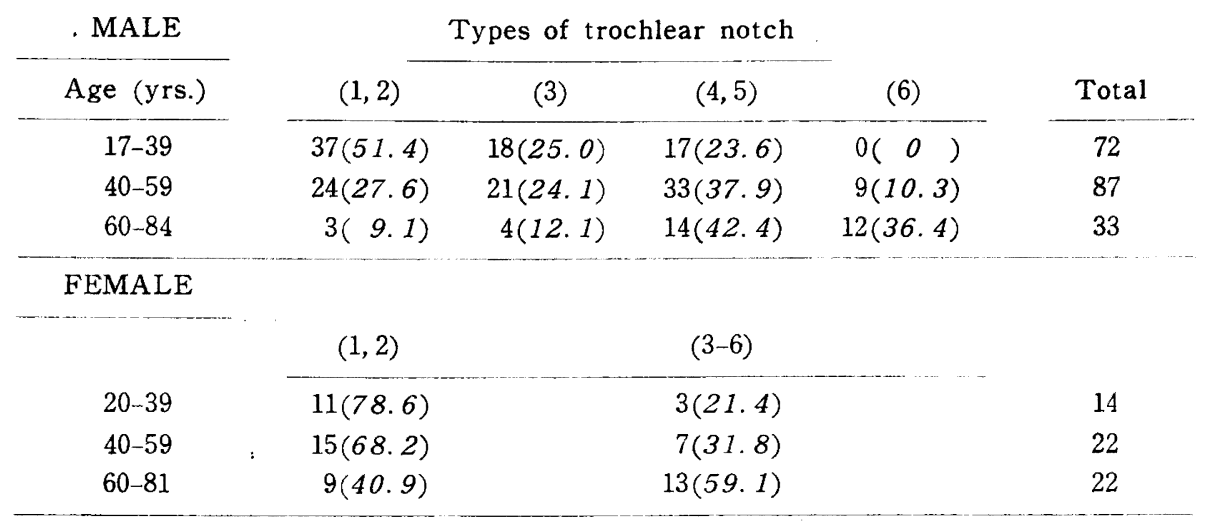

in another series of modern Japanese dried ulnae: from $10 \%$ in young adult male (under 30 years) to $21.2 \%$ in senile male group (over 50 years), though he might have used a criterium different from the present one.

The mean and standard deviation of the age in years of the skeletons showing each bipartient type of the trochlear notch are given in Table 5. There is a significant gradual increase of the mean age from the type of the least bipartient tendency to that of complete bipartition.

Table 5. The means and the standard deviations of the age (in years) for different bipartient types (sides pooled).

\begin{tabular}{cccccccc} 
& \multicolumn{3}{c}{ Male } & & \multicolumn{3}{c}{ Female } \\
\cline { 2 - 5 } \cline { 6 - 8 } Types & $n$ & $\bar{x}$ & $s$ & & $n$ & $\bar{x}$ & $s$ \\
\hline (1) & 7 & 32.1 & 12.15 & & 4 & 29.5 & 8.08 \\
(2) & 57 & 40.3 & 14.71 & & 31 & 50.8 & 19.84 \\
$(3)$ & 43 & 41.9 & 12.48 & & 11 & 60.2 & 18.36 \\
$(4,5)$ & 64 & 49.2 & 16.01 & & 10 & 52.0 & 12.01 \\
$(6)$ & 21 & 61.5 & 1229 & & 2 & 79.5 & - \\
\hline
\end{tabular}

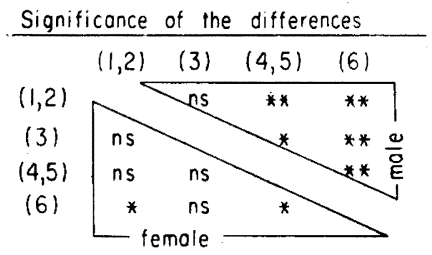

Asterisks: significont of the level of $0.05(*)$ or $0.01(* *)$.

The results of these two satistical analyses seem to confirm the age dependence of the bipartient tendency in the trochlear notch, i.e. the older the individuals, the more marked tendency toward bipartition of this articular surface. Incidentally, Heine (1925) observed that the transverse groove was entirely absent in the ulnae of about 50 autopsy cases of prepubertal children. 


\section{Relation with the Arthritic Tendency}

Articular surfaces are generally liable to degenerative changes in higher ages, which include the destruction of the articular cartilage and the proliferation of the bone tissue in the circumferential area of the articular surface. It was suspected that this might have some relationship to the bipartition of the trochlear notch surface.

In order to investigate the possible relationship between the bipartient and arthritic tendencies, an age group from 40 to 59 years of male with the largest sample size has been divided into two subgroups in two different ways: one by the age into $40-49$ and 50-59, and the other by arthritic tendency into normal and arthritic.

The arthritic tendency of each individual skeleton was diagnosed by observing the erosion of the articular cartilage at the distal end of right and left humeri, the distal end of right and left femora, and at all intervertebral articular facets, and the proliferation of bone at the margin of the body of all presacral vertebrae. Those skeletons showing definitive arthritic changes in more than two sites out of these six have been judged as arthritic.

As shown in Table 6, a significantly higher incidence of bipartient types (4-6) was seen in the ulnae of arthritic individuals than in those of normal ones, whereas no significant difference was found between the age groups 40-49 and 50-59. This implies that the bipartient tendency is more closely associated with the general arthritic tendency of the skeleton than directly with the age of individual.

Table 6. Tests for the male ulnae of 40-59 years of age.

\begin{tabular}{|c|c|c|c|c|}
\hline & $(1,2)$ & (3) & $(4-6)$ & Total \\
\hline $40-49$ & 12 & 16 & 25 & 53 \\
\hline $50-59$ & 12 & 5 & 17 & 34 \\
\hline Total & 24 & 21 & 42 & 87 \\
\hline
\end{tabular}

Test 2: Arthritis dependence

\begin{tabular}{lcrc|c} 
& $(1,2)$ & $(3)$ & $(4-6)$ & Total \\
\hline Normal & 14 & 13 & 14 & 41 \\
Arthritic & 10 & 8 & 28 & 46 \\
\hline Total & 24 & 21 & 42 & 87 \\
\hline \multicolumn{3}{c}{$\chi_{c}^{2}=6.257$} & \multicolumn{2}{c|}{$\mathrm{P}<0.05$}
\end{tabular}

\section{Incidences in the Iroquoian Material}

The sex identification of the Iroquoian ulnae was extremely difficult because of their provenance from a secondary group burial site. Only a rough estimation based on the general size and robustness was possible, leaving a large portion of the material unidentified.

Table 7 gives the incidences of the bipartient types for the prob- 
Table 7. Incidences of the bipartient types in the Iroquoian ulnae (right side only).

\begin{tabular}{lccccccc} 
& $(1)$ & $(2)$ & $(3)$ & $(4,5)$ & $(6)$ & $(7)$ & Total \\
\cline { 2 - 8 } $\begin{array}{l}\text { Male }(?) \\
(\%)\end{array}$ & 0 & 1 & 0 & 25 & 16 & 2 & 44 \\
$?$ & $(0)$ & $(2.3)$ & $(0)$ & $(56.8)$ & $(36.4)$ & $(4.5)$ & $(100)$ \\
$\begin{array}{l}\text { Female }(?) \\
(\%)\end{array}$ & 2 & 1 & 0 & 23 & 7 & 3 & 35 \\
$\begin{array}{l}\text { Total } \\
(\%)\end{array}$ & $(2.3)$ & $(26.4)$ & $(4.6)$ & $(50.6)$ & $(10.3)$ & $(5.7)$ & $(100)$ \\
& $(1.8)$ & $(15.1)$ & $(2.4)$ & $(55.4)$ & $(19.3)$ & $(6.0)$ & $(100)$ \\
\hline $\begin{array}{l}\text { Japanese male } \\
\text { right (\%) }\end{array}$ & $(4.2)$ & $(29.2)$ & $(22.9)$ & $(31.3)$ & $(12.5)$ & $(0)$ & $(100)$
\end{tabular}

ably male ulnae, probably female ulnae, unidentifiable ulnae, and the total series including 166 mature right side ulnae. When compared with the incidence data for the Japanese male right series, the total Iroquoian series, though it comprises a substantial female component, shows considerably higher proportions of strongly bipartient types than the former. The average age of death of the Japanese male series is 45.7 years and that of the Iroquoian series, though it is never known accurately, does not seem to exceed it by far, in view of the results of paleodemographic studies on other Iroquoian ossuary materials (Churcher \& Kenyon, 1960). This, therefore, strongly suggests that the Iroquoian ulnae of the same sex and average age with the Japanese material would show a considerably stronger tendency toward the bipartition of the trochlear notch surface. It seems that the high bipartient tendency in the Iroquoian ulnae is somehow associated with the generally high liability of the Iroquoian Indians to the osteoarthritic involvement.

\section{Incidences in the Ainu Ulnae}

The incidence data for the Hokkaido Ainu series are given in Table 8.

In the Ainu ulnae, the more marked bipartient types (4-6) occur

Table 8. Incidences of the bipartient types in the Ainu ulnae (sides pooled).

\begin{tabular}{lccccccc} 
& $(1)$ & $(2)$ & $(3)$ & $(4)$ & $(5)$ & $(6)$ & Total \\
\cline { 2 - 7 } Male & 5 & 13 & 17 & 17 & 30 & 13 & 95 \\
$(\%)$ & $(5.3)$ & $(13.7)$ & $(17.9)$ & $(17.9)$ & $(31.6)$ & $(13.7)$ & $(100)$ \\
Female & 2 & 25 & 7 & 13 & 8 & 9 & 64 \\
$(\%)$ & $(3.1)$ & $(39.1)$ & $(10.9)$ & $(20.3)$ & $(12.5)$ & $(14.1)$ & $(100)$ \\
Total* & 7 & 40 & 28 & 31 & 39 & 23 & 168 \\
$(\%)$ & $(4.2)$ & $(23.8)$ & $(16.7)$ & $(18.5)$ & $(23.2)$ & $(13.7)$ & $(100)$ \\
\hline
\end{tabular}

\footnotetext{
- Including the ulnae unidentifiable for the sex.
} 
in significantly higher proportions than in the Japanese ulnae both in the male and female $(P<0.01)$. On the other hand, the incidences of these types in the Ainu ulnae are again significantly lower than in the Iroquois ulnae $(P<0.01)$, even though the latter series includes much higher proportion of the female ulnae than the former. Relative frequencies of the bipartient types in these three different series are illustrated in Fig. 2. It is clearly shown that the more bipartient types (4-7) occur in an increasing order to the Japanese, the Ainu and the Iroquois, whereas the less bipartient types (1-3) occur in exactly the reverse order.

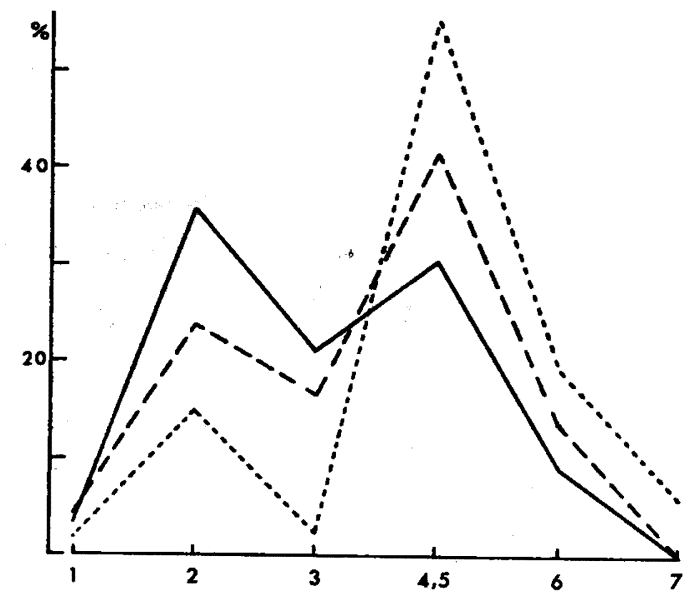

Fig. $\dot{2}$. Relative frequencies of the bipartient types of the trochlear notch in the ulnae of the Japanese (-), the Ainu (-- ), and the Iroquois (-----).

\section{Histological Examination}

Four fresh specimens of the trochlear notch from dissecting room, cadavers, showing cartilaginous crease (no. 1), partial osseous division (nos. 2 and 3), and complete osseous bipartition (no. 4), respectively, were decalcified, sagittally sectioned through the middle portion of the demarcating line, stained with $\mathrm{H} / \mathrm{E}$, and examined under a microscope. Macroscopic and histological descriptions of these four specimens follow.

No. 1 (Plate I, 1). 20 year old female. The articular surface is incompletely divided by a deep and narrow groove at the lateral part and a few discontinuous shallow grooves in the middle part. Histologically, these grooves are covered with the cartilage layer of normal thickness. Clearly this condition corresponds to the type (2) in macerated trochlear notch. 
No. 2 (Plate I, 2). 62 year old female. A yellowish thin band invades from the medial side across the guide ridge, leaving the lateral one third normally cartilaginous. The surface of the bony band is almost level with the normal articular cartilage superior and anterior to it. In the section, the bone tissue is locally elevated, though still covered with a thin cartilaginous layer, and the cartilage directly adjacent to this elevated bone shows a degenerative change which may be called the fibrillation. This condition seems to correspond to a transitional stage between the types (2) and (3).

No. 3 (Plate I, 3). 83 year old male. A reddish bony strip broader than that of no. 2 develops from the medial margin and reaches the lateral half of the trochlear notch. The lateral one third is separated by a short cartilaginous groove. The section through the middle portion shows the typical formation of the ossicle or the bony tubercle which is common to the types (3) to (5).

No. 4 (Plate I, 4). 82 year old male. The articular surface is completely bipartitioned by a wide reddish bony strip, the surface of which is again level with the normal cartilaginous part of the articular surface. In the section, the cartilage is entirely eroded by the underlying bone tissue along the demarcating strip and the bone and the joint cavity are intervened only by a very thin fibrous tissue, which seems to be the extention of the synovial membrane. This corresponds to the type (6) or (7) in macerated ulna.

\section{Summary and Conclusion}

An attempt was made to devise a sequent classification scheme for the widely variable bipartient tendencies of the articular surface of the trochlear notch. The proposed sequence of seven different types is shown in Fig. 1.

The validity of the morphological sequence of these types ranging from the non-bipartient to the completely bipartient was confirmed by examining the type combinations between the sides of the same individual skeletons.

Possible sex and age dependences of the bipartient tendency were tested by two statistical analyses, revealing significant sex and age differences: stronger tendency toward bipartition in the male than in the female, and also in the higher age than in the younger.

The test of the association between the bipartitional tendency of the trochlear notch and the general arthritic tendency of the entire skeleton confirmed a significant relationship between these two phenomena. This suggests a more direct association of the bipartient tendency with the general senility of the bone and joint rather than 
with the chronological age of individual. Much higher incidences of bipartite types in the Ainu and the Iroquoian ulnae than in the modern Japanese ulnae may be understood by such interpretation.

In addition to these statistical analyses on the macerated or excavated materials, a few fresh specimens were examined histologically. The results also suggested a successive change from normal cartilaginous demarcation, through the degeneration of the cartilage and the formation of a bony tubercle, to the entire replacement of the cartilage in the demarcating portion by bone tissue in extreme senility.

From anthropological point of view, the above results seem to devaluate the simple inter-populational comparison of the incidences of this trait without consideration of the age and sex compositions of the samples to be compared. However, if due considerations are paid to the age and sex factors, this trait can be a profitable subject of paleopathological study of skeletal populations.

\section{Acknowledgements}

Thanks are first due to Drs. J. E. Anderson, T. Ooe, and K. Mitsuhashi who afforded me opportunities to study the Iroquoian, the Ainu and the Japanese skeletal materials under their custody in Toronto, Tokyo and Sapporo. I am also indebted to Dr. F. Yamasaki for valuable advice as for histological preparations. Many persons cooperated in my project, among whom I wish to express my particular gratitude to Mr. P.C. Hartney in Toronto, Dr. T. Kamiya in Tokyo, and Mr. I. Sato in Sapporo.

\section{References}

Anderson, J.E. 1963. The people of Fairty : an osteological analysis of an Iroquois ossuary. National Museum of Canada, Bull. no. 193: 28-129.

Churcher, C. S. \& W. A. Kenyon, 1960. The Tabor Hill ossuaries : a study in Iroquois demography. Hum. Biol. 32: 249-273.

Fischer, E. 1906. Die Variationen an Radius und Ulna des Menschen. Z. Morph. Anthrop. 9 : 147-247.

Heine, I. 1925. Über die Querfurche am Olecranon. Anat. Anz. $59: 257-271$.

Henle, J. 1871. Handbuch der Knochenlehre des Menschen. 3te Aufl. Braunschweig.

Kiyono, K. \& T. Hirai, 1928. Anthropologische Untersuchungen über das Skelett der Tsukumo-Steinzeitmenschen. III. Die oberen Extremitäten. (in Japanese with German tables). J. Anthrop. Soc. Nippon 43 : Suppl. 179-301.

Kutsuna, M. 1930. (Bone morphology of the elbow joint and the supratrochlear foramen.) (in Japanese). Acta Anat. Nippon. 3 : 1049-1057.

Manouvrier, L. et R. Anthony, 1907. Études des ossements humains de la sépulture néolithique de Montigny-Esbly. Bull. Mém. Soc. Anthrop. Paris sér. 5, t. 8 : 537-563. 
Mizoguchi, S. 1957. Anthropological studies on the radius and ulna of Kyushu Japanese. (in Japanese with English summary). Jinruigaku-Kenkyu 4:237-272.

\section{Explanation of Plate}

Fresh right side trochlear notches from the dissection room cadavers (top) and their sagittal sections (bottom).

No. 1. 20 year old female (type 2)

No. 2. 62 year old female (type 2 or 3 )

No. 3. 83 year old male (type 4 or 5 )

No. 4. 82 year old male (type 6 or 7 ) 
Plate I

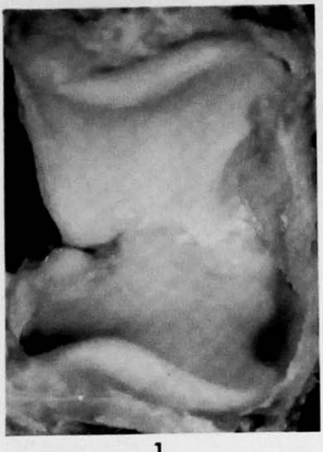

1

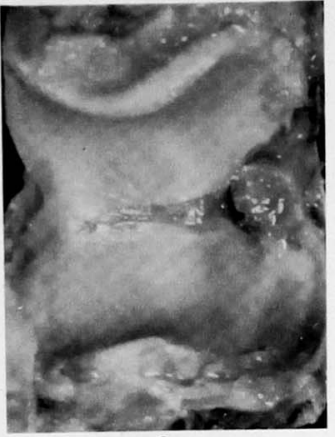

2

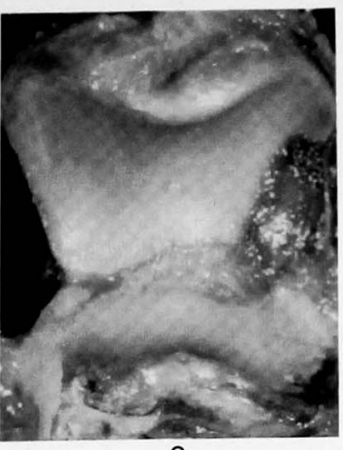

3
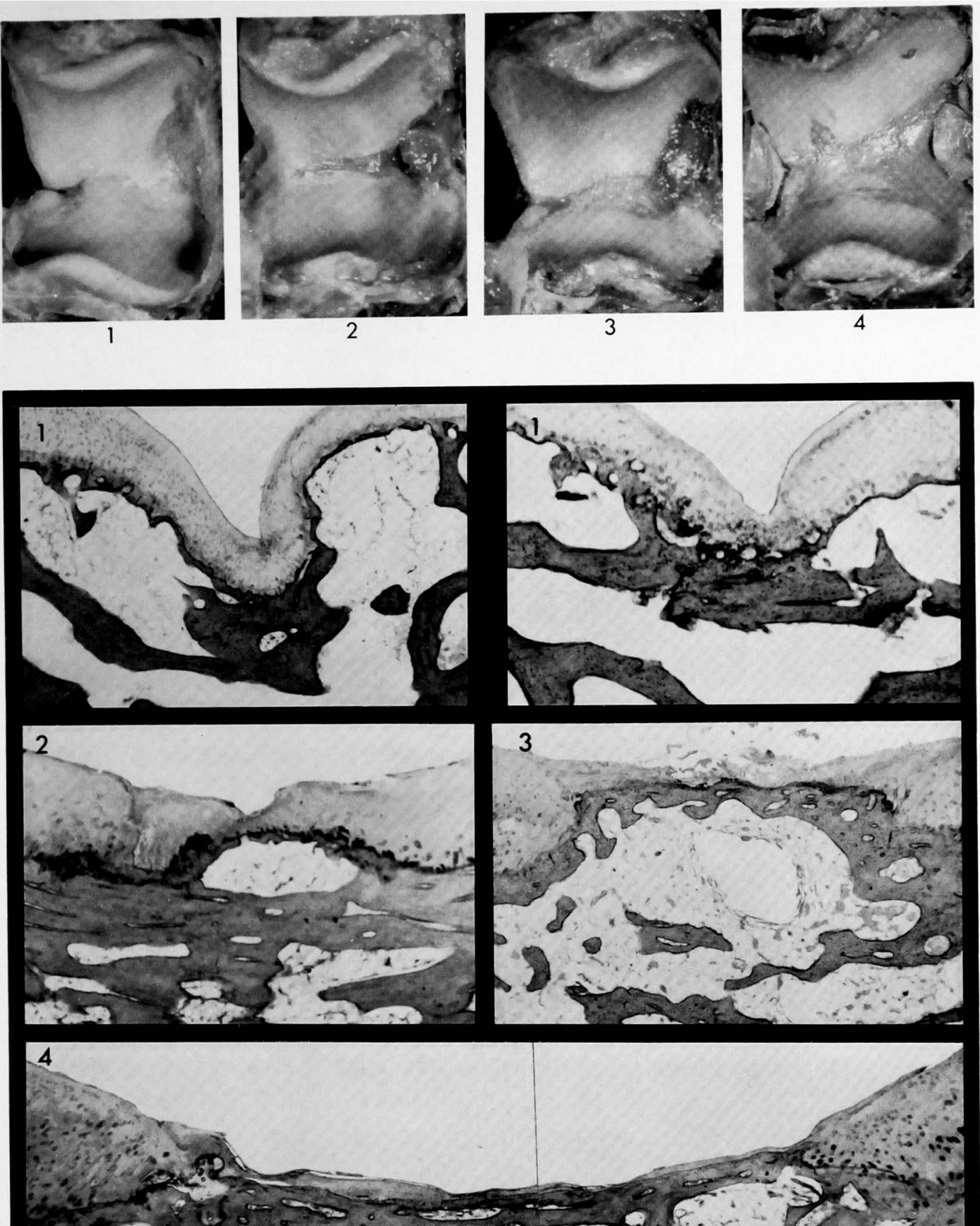

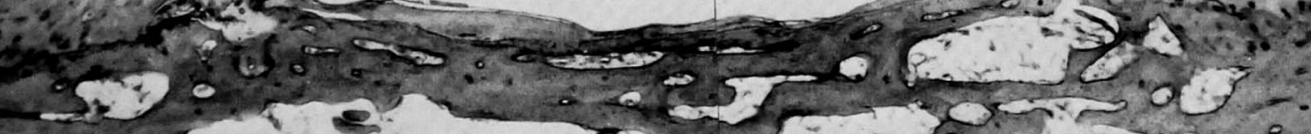

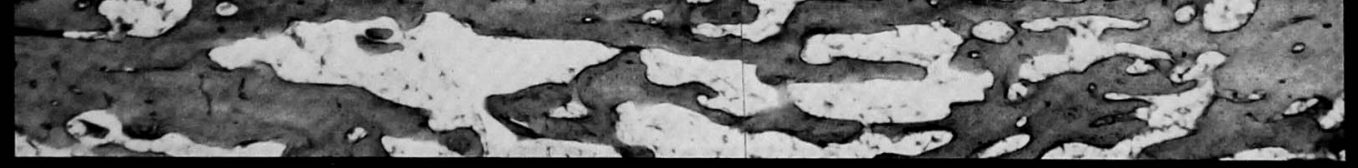

\section{B.Yamaguchi}

